\title{
Experimental Media Development for Learning Kinematics Using Jointed Robot Model
}

\author{
Siti Sendari ${ }^{1 *}$, Ilham Ari Elbaith Zaeni ${ }^{1}$, Moch. Burhanuddin Alfarobbi ${ }^{1}$ \\ ${ }^{1}$ Universitas Negeri Malang. Malang, Indonesia \\ *Corresponding author. Email: siti.sendari.ft@ um.ac.id
}

\begin{abstract}
This paper discusses about developing the learning media of kinematics using jointed robot models. The difficulty of learning kinematics is the high complexity of robot movements, while the number of degrees of freedom (DOF) is high. The DOF determines the movement of the robot joints to be more smooth, so each joint should be controlled accurately. The learning content consists of a theoretical concept of kinematic models and how this concept could be implemented as robot movements in real. In order to be more understandable, developing learning media is needed, which consists of jointed robot model as the practicing tool, practicum module and manual book. The learning content consists of a theoretical concept of kinematic models and how this concept is implemented as robot movements in real. The developing learning media is carried out regarding the learning media development method introduced by the Sugiyono's model. In order to observe whether the media could be valid for teaching-learning, evaluation of experts is needed. The results show that validation processes of experts are averaged as $91.2 \%$, which indicates the criteria of a product is very valid and suitable to be used as learning media to support learning activities of kinematics study.
\end{abstract}

Keywords: jointed robot, kinematics concept, experimental media

\section{INTRODUCTION}

Robotics is an important subject, which could be deal with designing, modelling, controlling, and usage of the robot for special purposes [1]. One of special robots is a legged robot, which designs consist of a large number of degree of freedom (DOF) to determine the locomotion and tasking abilities, such as humanoid robot [2] or animaloid robot [3]. The robot has a physical form and actuators designed to be able to move and resolve tasks [4]. In order to obtain a wellcoordinated movement, it is required to make a method of movement for the robot [5]. One such method is the Kinematics method.

Kinematics focus on study of its movement without involving the energy and force. There are some topics to be studied, such as kinematic analysis, inverse kinematic analysis, and modeling [1]. By using the kinematics, movement control of robots with high complexity of the movements, such as robot joints, can be precisely controlled [6]. In order to understand the kinematics concept, a learning media is needed to achieve the learning purposes [7]. Based on the curriculum in undergraduate at electrical engineering of education and undergraduate electrical engineering (TEUM Catalogue 2014), learning about the kinematics concept is determined as a part of robotics courses [8].

However, after observations at the robotics Laboratory and scientific papers on the TEUM library and discussions with several lecturers, especially in the Department of Electrical Engineering, the State University of Malang is known that the learning media for learning the kinematics concept still are urgent to be developed and improved. Therefore, in research and development it is focused to build the jointed robot modelling kinematics concept learning

\section{METHOD}

The methods used in this research and development of the learning media of this jointed robot using Sugiyono's development method [9]. The steps of the development method are shown at Figure 1 below.

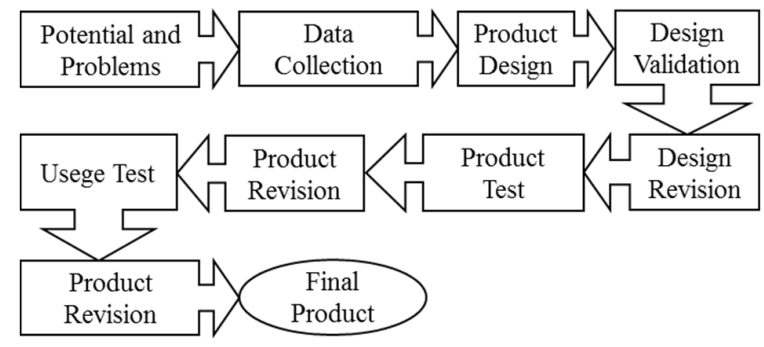

Figure 1 Design of Research and Development

In this research and development, the learning Media products are developed consisting of three things: practicing tool, practicum module and manual book. All three of these products are carried out the validation phase through design validation, product test and usage test that each of these stages is revised before entering the next stage. The initial design of the product first through design validation is done by two specialists/validators from the content and media 
side. After that, the product be tested at Department of Electrical Engineering undergraduate students 2015 who have been taking the robotics course as much as 50 respondents. In this study there are two test types, namely: the product test using a small group with 12 respondents and usage test using a large group with 38 respondents.

Data obtained from the research subject of both the validator and the respondent will be analyzed for the wellknown feasibility of the three learning media products that have been developed. The analysis formula to determine the feasibility level of the product has been developed (Akbar, 2013) namely:

$$
V=\frac{T_{S e}}{T_{s h}} \times 100 \%
$$

Explanation:

$$
\begin{array}{ll}
V & : \text { Validity of the subject } \\
T_{s h} & \text { : Maximum expected total score } \\
T_{S e} & \text { : Total score has been received }
\end{array}
$$

Based on the value of the validity obtained, the values are then entered in several criteria [10] which can be viewed in Table 1 .

\section{Table 1 Qualification of Validity Criteria}

\begin{tabular}{|l|l|l|l|}
\hline No & Percentage & Validation Criteria & Description \\
\hline 1 & $85 \%-100 \%$ & Very valid, usable without revision & Without Revision \\
\hline 2 & $70 \%-85 \%$ & Quite valid, usable but need to be revision & Minor Revision \\
\hline 3 & $50 \%-70 \%$ & Valid less recommended unused and need major revision & Major Revision \\
\hline 4 & $0 \%-50 \%$ & Invalid, shouldn't be used & Not Feasible \\
\hline
\end{tabular}

\section{RESULT AND DISCUSSION}

\subsection{Practicing tool}

The final design result of the practicing tool is shown at Figure 2. Basically, the trainer is divided into 2 main points, namely the trainer board and kinematic model where the basic frame is made of white acrylic with a thickness of $3 \mathrm{~mm}$. On the trainer board, there are four main parts: 1) test column of basic model which is used as the laying of the basic kinematic model that will be used for the practicum; 2) $2 \mathrm{D}$ coordinate system boards are used as pointer points of the practiced model; 3) I/O system as an integrated system package to control the model that is being practiced as well; 4) The USB port is used as a voltage source and a program converter from $\mathrm{PC}$ to basic kinematic model system.

In the kinematic model there are two focuses of learning, namely basic and applied. The basic kinematic model consists of the single link model, the SCARA arm model and the articulated arm model while the applied kinematic model is a tetrapod robot. The basic kinematic model is intended as an initial learning and gave a basic understanding of the kinematics concept while the applied kinematic model is intended as an application of the kinematics concept in making a constructed movement.

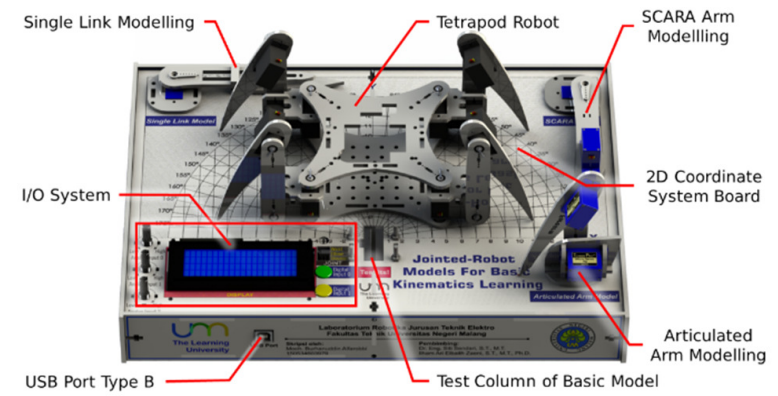

Figure 2 the Jointed Robot Model for Practicing Tool

\subsection{Learning Media in the Form of Printed Books}

There are two things that are intended for this print learning media, namely: the practicum module and the guidebook. The practicum module is used as a learning resource as well as a practical guide for the learning process that supports an understating of kinematics concept. The practicum module that has been developed, contains four original learning content: 1) Introduction of Kinematics; 2) Introduction of Jointed Robot; 3) Simple Robot Arm Configuration; 4) Four-Legged Robot System. The module practicum is writing structure refer by Daryanto [11]. There are 2 types of practicum modules that are for lecturers and students. The differentiator of both is the availability of answer keys and assessment instructions that are only found at practicum module for lecturers. Meanwhile, this trainer handbook contains specifications, kinematic model construction, how to use, tutorials and other information related to jointed 
robot modelling. The front cover display of the practicum module and the guidebook is shown in Figure 3.

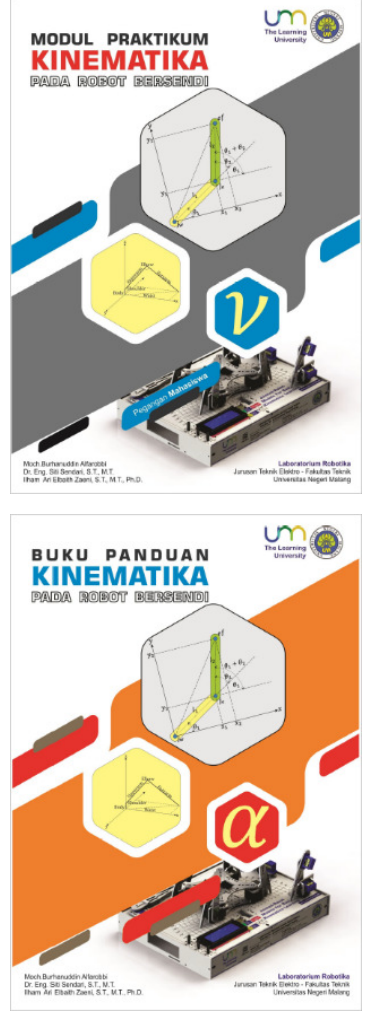

Figure 3 Front Cover of the Printed Book Learning Media

\subsection{Design Validation}

In the validation of this design there are two sides of the assessment from the material side and the media side carried out by two spesialists / validators. Design validation must be carried out before the trial is implemented on the respondent. Further discussion about material validation and media validation will be explained as follows.

\subsubsection{Content Validation}

In the validation of content there are four aspects of quantitative assessment namely: comformity, completeness, language and communication as well as accuracy. The results of content validation are shown at Table 2 .

Based on the data validation results of the material at Table 2 assessed by the two spesialists, the lowest aspect assessment lies in language and communication aspect with an average percentage validity of $90.63 \%$ while the highest aspect evaluation lies in the aspect of conformity with the average percentage of validity $97.50 \%$ Based on the average percentage of validity of the two spesialists obtained is $92.29 \%$, so the product is declared very valid in terms of content assessment.

\subsubsection{Media Validation}

In the validation of media there are four aspects of quantitative assessment namely comfomity, media capability, ease of use as well as communication and visuals. The results of media validation are shown in Table 3.

Based on data from the results of media validation in Table 3 , which was assessed by the two spesialists, the lowest aspect assessment lies in the ability of the media with an average percentage of validity of $90.63 \%$ while the highest aspect rating lies in ease of use with an average percentage of validity of $100.00 \%$. Based on the average percentage of validity of the two spesialists obtained, namely $94.32 \%$, the product was declared very valid in terms of media assessment.

\subsection{Testing}

There are two kinds of these test, namely: product test and usage test. In these two test there are five aspects of quantitative assessment, namely: conformity, completeness, media capability, ease of use as well as communication and visuals. The subject research in this test is Department of Electrical Engineering undergraduate students 2015 who have been taking the robotics course as much as 50 respondents.

\subsubsection{Product Testing}

In this test, the 12 respondent divided by four group. At every group try the one topic at practicum module. Then they fill the of research instrumen of respondent. The results of product test are shown in Table 4 below.

Based on the product test data at Table 4 which is the result of the assessment of the small group respondents, the lowest aspect evaluation lies in completeness with a percentage of validity of $86.67 \%$ while the highest aspect evaluation lies in conformity with the average percentage validity of $92.19 \%$. the lowest group evaluation lies in at Group III with a percentage of validity of $87.08 \%$ while the highest group evaluation lies at group IV with the average percentage validity of $94.22 \%$. Based on the average percentage of validity of both obtained that is $89.52 \%$, then the product is declared to be very valid based on the respondents' assessment of the usage test.

\subsubsection{Usage Testing}

In this step, the 38 respondent just subjective assessment at the learning media has being developed. The results of usage test are shown in Table 5 below. 
Based on the usage test data at Table 5 which is the result of the assessment of the large group of respondents, the lowest aspect assessment lies at capability media with a percentage validity of $86.62 \%$ while the highest aspect rating is at conformity with the average percentage of validity of $91.61 \%$. Based on the average percentage of validity of all aspects obtained that is $88.67 \%$, then the product is declared to be very valid based on the respondents' assessment of the usage test.

Table 2 Results of Content Validation by Both Validators

\begin{tabular}{|l|l|l|l|l|l|}
\hline \multirow{2}{*}{ No } & \multirow{2}{*}{ Aspects } & \multicolumn{3}{|c|}{ \% Validation } & \multirow{2}{*}{ Description } \\
\cline { 3 - 6 } & & Specialist I & Specialist II & Average & \\
\hline 1 & Conformity & 100 & 95 & 97.5 & Very valid \\
\hline 2 & Completeness & 92.25 & 92.25 & 92.5 & Very valid \\
\hline 3 & Language and Communication & 83.33 & 83.33 & 83.33 & Very valid \\
\hline 4 & Accuracy & 100 & 91.67 & 95.83 & Very valid \\
\hline & Percentage of Subject & 93.96 & 90.29 & 92.29 & Very valid \\
\hline
\end{tabular}

Table 3 Results of Media Validation by Both Validators

\begin{tabular}{|l|l|l|l|l|l|}
\hline \multirow{2}{*}{ No } & \multirow{2}{*}{ Aspects } & \multicolumn{3}{|c|}{ \% Validation } & \multirow{2}{*}{ Description } \\
\cline { 3 - 6 } & & Specialist I & Specialist II & Average & \\
\hline 1 & Conformity & 95 & 95 & 95 & Very valid \\
\hline 2 & Completeness & 93.95 & 87.5 & 90.63 & Very valid \\
\hline 3 & Language and Communication & 100 & 100 & 100 & Very valid \\
\hline 4 & Accuracy & 91.67 & 91.67 & 91.67 & Very valid \\
\hline & Percentage of Subject & 95.1 & 93.54 & 94.32 & Very valid \\
\hline
\end{tabular}

Table 4 Products Testing Assessment Results

\begin{tabular}{|c|c|c|c|c|c|c|c|c|}
\hline \multirow{2}{*}{ No } & \multirow{2}{*}{ Aspects } & \multicolumn{4}{|c|}{ Tse Score per Group } & \multirow[b]{2}{*}{ Tsh } & \multirow[b]{2}{*}{$\mathbf{V}_{@ \text { Aspect }}$} & \multirow{2}{*}{ Description } \\
\hline & & I & II & III & IV & & & \\
\hline 1 & Conformity & 43 & 47 & 43 & 48 & 48 & $92.19 \%$ & Very valid \\
\hline 2 & Completeness & 48 & 54 & 50 & 56 & 60 & $86.67 \%$ & Very valid \\
\hline 3 & Media Capability & 31 & 30 & 31 & 33 & 36 & $86.81 \%$ & Very valid \\
\hline 4 & Ease of Use & 23 & 22 & 21 & 23 & 24 & $92.71 \%$ & Very valid \\
\hline 5 & Communication and Visual & 65 & 57 & 64 & 65 & 72 & $87.15 \%$ & Very valid \\
\hline & $\mathrm{V}_{@ \text { Group }}$ & $88.36 \%$ & $88.42 \%$ & $87.08 \%$ & $94.22 \%$ & $100 \%$ & $89.52 \%$ & Very valid \\
\hline
\end{tabular}

Table 5 Usage Testing Assessment Results

\begin{tabular}{|l|l|l|l|l|l|}
\hline \multirow{2}{*}{ No } & \multirow{2}{*}{ Aspects } & \multicolumn{2}{|c|}{ Score } & \multirow{2}{*}{ \% Average } & \multirow{2}{*}{ Description } \\
\cline { 3 - 6 } & & Tsh & Tse & & \\
\hline 1 & Conformity & 608 & 558 & 91.77 & Very valid \\
\hline 2 & Completeness & 760 & 676 & 88.94 & Very valid \\
\hline
\end{tabular}




\begin{tabular}{|l|l|l|l|l|l|}
\hline 3 & Media Capability & 456 & 398 & 87.28 & Very valid \\
\hline 4 & Ease of Use & 304 & 272 & 89.47 & Very valid \\
\hline 5 & Communication and Visual & 912 & 810 & 88.81 & Very valid \\
\hline & Total Score & 3040 & 2714 & & \\
\hline & Percentage of Subject & & & 89.27 & Very valid \\
\hline
\end{tabular}

\section{CONCLUSION}

Based on the final results obtained from the research validation phase of the design and testing, the overall average percentage was $91.2 \%$. From the value of the validity of the product stated in the criteria are very valid and fit to be used to train the kinematics aided by joint robot modeling.

\section{ACKNOWLEDGMENT}

This research was funded by PNBP Malang State University Budget Year 2020.

\section{REFERENCES}

[1] K. Raza, T. Aized, and N. Abbas, "Journal of King Saud University - Engineering Sciences Kinematic analysis and geometrical improvement of an industrial robotic arm," J. King Saud Univ. - Eng. Sci., vol. 30, no. 3, pp. 218-223, 2018.

[2] S. Sendari, D. Lestari, C. U. Kusumohadi, F. S. Wibowo, and K. Anam, "Integrating embedded color vision to Bioloid robot for playing soccer," in Proceedings - International Conference on Signals and Systems, ICSigSys 2017, 2017.

[3] G. A. Prasetyo, "Development of the Gait Planning for Stability Movement on Quadruped Robot," 2019 Int. Electron. Symp., pp. 376-381, 2019.

[4] V. Tech, W. S. Rone, V. Tech, V. Tech, and V. Tech, "Robotic Modular Leg : Design, Analysis, and Experimentation," vol. 9 , no. April, pp. 1-6, 2017.

[5] D. Xi and F. Gao, "Type Synthesis of Walking Robot Legs," 2018.

[6] M. Garcia-Lopez, C, E. Gorrostieta-Hurtado, J. Ramos-Arreguin, M, E. Vargas-Soto, A. Sotomayor-Olmedo, and J. C. Moya Morales, "Kinematic analysis for trajectory generation in one leg of a hexapod robot .," vol. 3, pp. 342-350, 2012.

[7] J. W. Hurst, "Robot Leg Design : A Constructive Framework," IEEE Access, vol. 6, pp. 54369-54387, 2018.

[8] S. Sendari, H. Elmunsyah, and Y. Dwi, "Six-Legged Animaloid Robot as a Trainer for Robotic Course," pp. 199-202, 2015.

[9] R. Wahyu, Y. Putra, J. Fakhri, and D. Fitriani, "The Development of Teaching Materials Gamification-Based Problem Solving on the Material in Terms of Four," vol. 2, no. 2, pp. 58-63, 2019.

[10] D. O. F. A. Learning-oriented, T. Of, E. Childhood, and L. P. Subject, "TEXTBOOK OF EARLY CHILDHOOD EDUCATION," vol. 4, pp. 102-110, 2018.

[11] R. Danniarti and M. Kristiawan, "DEVELOPING A MODULE OF TEACHERS' PROFESSIONALISM BASED EFFECTIVE TEACHERS '," pp. 650-663. 